\title{
LEARNING BY DOING E COMPLEXIDADE: um diálogo entre a teoria e a prática
}

\author{
Roque Corrêa Júnior \\ Dilmeire Sant'Anna Ramos Vosgerau \\ Pura Lúcia Oliver Martins
}

\section{Resumo}

Este diálogo é um excerto de uma pesquisa em desenvolvimento sobre a formação de professores em educação musical apoiada pelas tecnologias digitais. $\mathrm{O}$ interesse em aproximar as duas teorias surgiu do referencial teórico usado no desenvolvimento do projeto de mestrado do autor (Roger Schank) e do referencial teórico proposto para uma matéria da grade curricular do mestrado em educação da PUC-Paraná (Edgar Morin). Tem como objetivo criar um diálogo entre o Learning by Doing, de Roger Schank, com os princípios da complexidade de Edgar Morin, indicando quais são os pontos semelhantes nas duas teorias. Além disso, buscou-se compreender como essas teorias contemporâneas abordam do conhecimento e a forma como o sujeito do conhecimento é visto.

Palavras-chave: complexidade; learning by doing; aprendizagem; teoria e prática.

\section{LEARNING BY DOING AND COMPLEXITY: a dialogue a dialogue between theory and practice}

\begin{abstract}
This dialogue is an excerpt of research in progress on teacher education in music education supported by digital technologies. The interest in approaching the two theories arose from the theoretical framework used in the development of the author's master's project (Roger Schank) and the proposed theoretical framework for a subject in the curriculum of the PUC-Paraná Master of Education (Edgar Morin). It aims to create a dialogue between Roger Schank's Learning by Doing, and Edgar Morin's Principles of Complexity, indicating the similar points in the two theories. In addition, we sought to understand how these contemporary theories deal with knowledge and the way the subject of knowledge is viewed.
\end{abstract}

Keywords: complexity; learning by doing; learning; theory and practice.

\section{APRENDER HACIENDO Y COMPLEJIDAD:} un diálogo entre la teoría y la práctica

Resumen

Este diálogo es un extracto de una investigación en curso sobre la formación del profesorado en educación musical con el apoyo de tecnologías digitales. El interés en abordar las dos teorías surgió del marco teórico utilizado en el desarrollo del proyecto de maestría del autor (Roger Schank) y el marco teórico propuesto para una asignatura en el plan de estudios del Máster de Educación PUC-Paraná (Edgar Morin). Su objetivo es crear un diálogo entre Learning by Doing de Roger Schank y los Principios de Complejidad de Edgar Morin, indicando los puntos similares en las dos teorías. Además, buscamos comprender cómo estas teorías contemporáneas tratan con el conocimiento y la forma en que se ve el tema del conocimiento.

Palabras clave: complejidad; learning by doing; aprendizaje; teoría y práctica. 


\section{INTRODUÇÃO}

A educação na contemporaneidade vem ao encontro de novos e vastos desafios, estes se tornaram exponenciais com o advento da internet, com mais rigor a partir do final da década de 1990. Nessa perspectiva, a educação 4.0 - permeada pelos aparatos tecnológicos, pela velocidade da informação e pela consequente inserção dessas ferramentas no cotidiano escolar - proporciona novos ambientes de ensino e aprendizagem, os quais requerem um novo pensar, tanto do educador quanto do educando, originando novos olhares para a educação moderna.

Esses olhares estão em busca de novas abordagens, novos conceitos em educação, tendo em vista que as necessidades da sociedade mudam com o passar dos anos, logo, torna-se imprescindível identificar novas abordagens pedagógicas que possam orientar os caminhos a serem trilhados. Para contribuir para essa busca, este diálogo traz duas teorias, uma proposta no campo das ciências sociais e a outra no campo da psicologia da aprendizagem: a complexidade e a Learning by Doing (doravante $L B D$ ). A primeira, sendo um vasto campo de estudos, compreende o conhecimento como algo em constante construção, o qual não deve ser fragmentado; já a $L B D$, advinda da corrente pragmatista de John Dewey ${ }^{1}$, pauta a aprendizagem no fazer.

A aproximação entre essas duas teorias justifica-se ao considerar que, em uma sociedade em constante mudança, é necessário entender como os sujeitos podem aprender em um "mundo complexo". Nessa perspectiva, a $L D B$ tem sido uma das alternativas para essa aprendizagem.

Ressalta-se que o fato de discutir e se apropriar de novas propostas não significa esquecer ou ofuscar o conhecimento estabelecido ao longo do tempo, mas complementar o que já foi definido no campo da educação. Sendo assim, esses novos processos, métodos e teorias, a depender do conceito etimológico empregado, têm apenas uma preocupação: o repensar a aprendizagem, logo, a forma como os indivíduos ensinam e aprendem.

É diante dessas inquietações que se propõe a questão central deste ensaio: de qual forma as propostas da $L B D$ podem responder aos princípios da complexidade? Para tanto, faz-se necessário contextualizar as duas teorias indicando como são conceituadas e de que modo podem contribuir para o ensino e para aprendizagem.

\section{DESVELANDO OS AUTORES}

Edgar Morin² é um estudioso das grandes transformações sociais do século XX, as quais, segundo o autor, são de ordem cultural e científica, portanto, não estão isoladas, visto que fazem parte de um sistema complexo, no caso, o pensamento complexo. Para Morin (1991), “[...] a complexidade é um tecido (complexus: o que é tecido em conjunto) de constituintes heterogêneos inseparavelmente associados: coloca o paradoxo do uno e do múltiplo" (MORIN, 1991, p. 17), o qual envolve os mais diversos aspectos de conhecimento humano e as suas relações sociais.

A complexidade não pode ser resumida a um método, mas a uma forma de dialogar com o mundo e com o conhecimento. Nesse sentido, "[...] nenhum sistema é capaz de auto-explicar-se

\footnotetext{
${ }^{1}$ John Dewey (1859-1952) é possivelmente o maior autor da educação nova; ou, como ele preferia caracterizar, da educação progressiva. Nascido em Burlington, Vermont, nos Estados Unidos da América, é considerado por muitos como o maior teórico da pedagogia do século XX. É, com Willian James, um dos principais representantes do pragmatismo norte-americano. (CARLOTA, 2006, p. 602)

${ }^{2}$ Edgar Nahoum nasceu em 1921, no oitavo dia do mês de julho em Paris. Filho único de um casal de judeus sefarditas - descendentes de judeus expulsos da península ibérica no final do século XV (DIAS, 2007, p. 77). Do final da década de quarenta do século XX até nossos dias a incessante produção intelectual de Edgar Morin acumula dezenas de obras que se estendem por vários campos do conhecimento: a antropossociologia fundamental, a cultura de massa, a política, a educação e o ciclo de O Método. (DIAS, 2007, p. 81)
} 
[sic] totalmente, nem de auto-exprimir-se [sic]" (MORIN, 1991, p. 92), logo, não se pode achar a explicação para tudo na complexidade, pois isso limitaria tudo aquilo a que ela se propõe quebrar.

Assim, ao propor essa teoria, Morin $(1991,2000)$ dialoga com o fato de que, ao longo do tempo, o conhecimento se tornou tão minucioso, prescritivo e fragmentado que já não é mais possível entendê-lo de maneira contextualizada, apenas como um monte de pedaços embaralhados em um campo epistemológico. Nessa lógica, assim como um indivíduo pode aprender a apertar um parafuso em uma linha de produção e tornar-se incapaz de entender como funciona o carro que ele ajuda a construir; outro indivíduo pode aprender muito sobre genética e não entender sobre o funcionamento de outras áreas da biologia e sua relação com o ambiente (MORIN, 1991, 2000).

Essa visão de mundo incapacita mais do que habilita a compreensão dos fenômenos do mundo (MORIN, 1991), nesse sentido, a complexidade "[...] é uma palavra problema e não uma palavra solução" (MORIN, 1991, p. 8), uma quebra de paradigma que se estende por todos os ramos da ciência. Dessa forma, o diálogo com o real é parte da premissa de que a ciência deve considerar os mais variados aspectos do conhecimento: o epistemológico, o ontológico e o metodológico, além de considerar as mais variadas dimensões do ser humano: o espiritual, o físico e o biológico (MORIN, 2000).

Trata-se da "eliminação da simplicidade" (MORIN, 1991, p. 8): questionar o que há tempos a ciência nos traz como verdade. Isso não é uma situação de negação, mas sim de construção, na qual a totalidade não é e nunca foi a verdade. Assim, se o conhecimento se materializa nas mais variadas formas, então é necessária uma tomada de "Consciência Radical" (MORIN, 1991, p. 12), a fim de que possamos quebrar esse paradigma, contextualizá-lo com nossas reais necessidades, para que o conhecimento realmente traga significados importantes para a vida em sociedade e para a significação do cosmos e do universo.

Destarte, o que deve ser estabelecido neste meio é que o erro não deve ser visto como um tendencioso caminho à imperfeição, pelo contrário, é parte importante da constituição desse conhecimento, por meio do qual se estabelece uma relação de interdependência, tendo em vista que "[...] dependemos de uma educação, de uma linguagem, de uma cultura, de uma sociedade, dependemos bem entendido, de um cérebro, ele próprio produto de um programa genético e dependemos também dos nossos genes" (MORIN, 1991, p. 80).

Ou seja, estamos em uma construção social de conhecimento passível ao erro, mas, na visão de Morin, na visão complexa, "[...] quando se chega por vias empírico-racionais às contradições, isto significa não um erro, mas o atingir de uma camada profunda da realidade que, justamente porque é profunda, não pode ser traduzida para a nossa lógica" (MORIN, 1991, p. 82). Desse modo, estamos constantemente fadados à procura, ao questionamento, pois nem sempre teremos respostas prontas; serão as perguntas que direcionarão os caminhos por essa busca de conhecimento.

Por essa lógica, sobre a busca e a aquisição de conhecimento, recorre-se a Roger C. Schank $(1999)^{3}$, que propõe uma ressignificação para o conceito da LBD proposta por Dewey e, consequentemente, uma atualização dos conceitos de aprendizagem.

Schank (1999) alega que grande parte de nossas aprendizagens são inconscientes, não acontecem com aulas teóricas ou pela memorização, que são processos conscientes. Por isso, a proposta da LBD é promover a prática, pois esta sim pode promover a aprendizagem inconsciente. Nesse sentido, um dos motivos para não se ter a aprendizagem prática dentro da escola, deve-se

\footnotetext{
${ }^{3}$ O Dr. Schank é membro do AAAI (Association For The Advancement Of Artificial Intelligence), fundador da Cognitive Science Society e cofundador do Journal of Cognitive Science. Ele é Ph.D. em Linguística pela Universidade do Texas. Um dos principais pesquisadores mundiais em Inteligência Artificial, o Dr. Schank é autor de mais de 125 artigos e publicações. Ele escreveu mais de 30 livros. Disponível em https://www.rogerschank.com/about.
} 
ao fato da atividade prática não ter sido completamente entendida pelos educadores (SCHANK, 1999).

Apesar disso, o autor alega que essa aprendizagem é mais comum do que se imagina, pois, sempre que fazemos algo, somos direcionados automaticamente para uma experiência anterior, no qual o raciocínio é baseado em situações vividas e não exatamente em regras. Isso, na maioria das vezes, é feito inconscientemente, a fim de mesclar duas vivências com o objetivo de entender a atual que está sendo vivida. Nos casos em que não é possível uma mescla, Schank (1999) ressalta que uma nova experiência é criada, a qual fica armazenada de forma inconsciente até que o cérebro, em uma nova experiência, a reivindique. Essas experiências são os scriptlets ${ }^{4}$.

Segundo Schank (1999), a LBD é composta de scriptlets. "Nossas habilidades são ligadas em scriptlets. Quando dizemos que sabemos como fazer algo, estamos muitas vezes referindo-nos a um ou mais scriptlets que adquirimos ao longo dos anos" (SCHANK, 1999). Esses conhecimentos, na maioria das vezes, são inconscientes, sendo que uma habilidade pode conter um ou vários scriptlets, mas um scriptlet não poder ser uma habilidade em sua totalidade.

Existem três formas de scriptlets: perceptivos, cognitivos e físicos. Os físicos referem-se a operações mecanizadas, tal como apertar uma campainha; os cognitivos são conhecimentos sobre o uso das coisas e sobre as coisas, por exemplo: saber que a utilidade da campainha é para chamar alguém e que, se apertarmos com muita força e sucessivamente, ela pode ser danificada; já os perceptivos permitem identificar situações no ambiente e de perigo, bem como perceber sentimentos que permeiam as ações humanas, por exemplo: ao apertar a campainha, percebo que o cachorro latiu, logo, preciso me distanciar do local (SCHANK, 1999). Esses scriptlets podem atuar em conjunto, separados ou até mesmo sozinhos, o fato é que, conforme o autor, não se pode ensinar um scriptlet simplesmente porque ele é fácil de ser aprendido, pois é preciso um motivo, uma finalidade para essa aprendizagem. Sendo assim, o scriptlet é a essência da prática com sentido.

Para ilustrar o conceito, o autor apresenta como exemplo o ato de enviar um e-mail: na busca de um objetivo central, que é o de enviar e receber mensagens, o indivíduo testa várias fermentas de e-mail, aprende a anexar um arquivo e/ou uma foto, aprende a responder a um e-mail etc; a praticar esses passos o indivíduo está aprendendo scriptlets (SCHANK, 1999).

Diante disso, Schank (1999) sugere que o foco esteja em novas vivências, colocando o educando em situações diversas e favorecendo a criação de possibilidades de resolução de problemas, dessa forma "[...] os alunos irão facilmente desenvolver scriptlets no curso natural da busca de um objetivo" (SCHANK, 1999, p. 176). Esses scriptlets, ao serem apropriados, poderão ser entendidos em suas mais variadas perspectivas, de como e por quê acontecem. Além disso, o autor ressalta que é essencial que os currículos das instituições de ensino sejam repensados com vistas a incorporar o cotidiano e as vivências reais dos educandos, para que assim, e somente assim, a aprendizagem possa ser contextualizada e entendida, tanto pelo educador, quanto pelo educando.

\section{APROXIMANDO AS TEORIAS}

O ponto-chave para entender a complexidade e a $L B D$ é perceber que há vontade para alterar a forma como se aprende e se ensina. Nessa lógica, se a complexidade é uma quebra de paradigma por ir de encontro aos princípios tradicionais de conhecimento científico, englobando então todas as áreas do conhecimento humano; a $L B D$, sumariamente, constitui essa quebra de paradigma propondo um ensino que geralmente não acontece na sala de aula: o do aprender fazendo.

Como ressalta Schank (1999), isso ainda não é geralmente empregado pela falta de conhecimento. E é justamente nessa falta que está baseada a crítica da complexidade. Esse

\footnotetext{
${ }^{4}$ Segundo Schank, eles geralmente são "habilidades de nível muito baixo que praticamos muitas vezes ao longo dos anos" (SCHANK, 1999). Praticamos scriptlets quando estamos constantemente buscando o mesmo objetivo.
} 
conhecimento não é conteudista ou tradicional, mas sim aquele que pode fazer com que todas as áreas do conhecimento dialoguem de forma sadia conversando também com o ser humano físico, biológico, psíquico, cultural, social e histórico (MORIN, 2000).

Morin, ao apontar que devemos "[...] confiar nas possibilidades cerebrais do ser humano ainda em grande parte inexploradas; [indica que] a mente humana poderia desenvolver aptidões ainda desconhecidas pela inteligência, pela compreensão, pela criatividade" (MORIN, 2000, p. 75). Schank (1999) certamente corrobora com Morin (2000), ao trazer o conceito de aprendizagem inconsciente. Isso evidencia que existem tipos de aprendizagem que comumente não podem ser explicados, nem compreendidos (ainda), mas que devem, sim, ser considerados e gradualmente entendidos sob a luz da ciência.

Esse conceito de aprendizagem inconsciente nos faz notar que a LBD é também uma proposta puramente complexa, uma vez que, ao aprender fazendo, podemos encontrar os aspectos: físico, ao usar a coordenação motora para a prática; biológico, o qual nos faz sentir sensações, cujas experiências podem ativar neurotransmissores, como a dopamina; psíquico, marcado pela aprendizagem inconsciente; cultural, ao aproximar a aprendizagem ao contexto do estudante; social, por ser a prática um processo que, muitas vezes, ocorre em grupo; e, por fim, histórico, visto que o processo de aprendizagem está conectado a um sentido maior tornando a aprendizagem significativa e, por conseguinte, o educando um sujeito histórico e construtor de seu próprio conhecimento.

Nesse sentido, Morin (2000) destaca que a condição humana deveria ser o objeto essencial de todo ensino. Ora, não somos seres que fazem, atuam, agem? Não só na sociedade, mas também na nossa aprendizagem? O homem paleolítico, por exemplo, não aprendeu a fazer na teoria seus instrumentos e depois os construiu. Pelo contrário, ele primeiro, por meio da prática, viu que algumas formas de pedra serviam para determinados tipos de atividades e só depois começou a replicá-las. Uma criança aprende primeiro a falar e só depois começa a entender quais são os signos e as interpretações do alfabeto. Por essas e por outras características é que somos seres práticos, logo, a LBD é reflexo do que a condição humana pode nos promover: a ação.

Para Morin (2000), essa ação é ressignificada como "ecologia da ação", pois tudo o que o ser humano faz reflete no seu meio pessoal, social e consequentemente ecológico. Para o autor, às vezes podemos ter a impressão de que a ação é algo simplificado, no entanto, “[...] a ação é decisão, escolha, mas é também uma aposta" (MORIN, 2000, p. 86).

Isso nos faz inferir que a LBD proposta por Schank (1999) é complexa no sentido de proporcionar um universo de possibilidades que se mostram por meio da prática, mas também é complexa pela prática estar sujeita ao "[...] aleatório, acaso, iniciativa, decisão, inesperado, imprevisto, consciência de derivas e transformações” (MORIN, 2000, p. 87). Ou seja, se para Morin (2000) e Schank (1999) a ação está permeada pelas incertezas, é possível deduzir que nossa aprendizagem também está sujeita ao erro.

Sobre o erro, Morin $(1991,2000)$ alerta que a educação deve mostrar que não existe conhecimento que não esteja ameaçado em algum nível por ele. O erro para o autor não é algo depreciativo, mas uma forma de estar ciente das imperfeições que nos cercam e tentar repará-las de alguma forma, de outra maneira, o erro faz parte da aprendizagem, assim como os acertos.

Nessa lógica, Schank (1999) parte do mesmo pressuposto: a partir da prática, os erros aparecem, e quando reaparecem, já aprendemos os scriptlets necessários para agir diante de determinadas situações, sabendo então como lidar e como conseguir melhorar a nossa ação, logo, a prática está sempre aliada ao erro. O erro está para Morin, assim como está para Schank.

Para superar essas incertezas, e consequentemente os erros, Morin (2000) ressalta a importância de criar estratégias, pois elas elaboram "[...] um cenário de ação que examina as certezas e as incertezas da situação, as probabilidades, as improbabilidades." (MORIN, 2000, p. 90). Essas 
estratégias, caso sejam trazidas ao contexto da LBD, representam os scriptlets, uma vez que eles são responsáveis por possibilitar ao indivíduo pensar sobre a sua prática. Esse caminho com a estratégia, que será trilhado com mais precaução e organização, ainda não estará livre das incertezas, mas com certeza estará mais preparado para o inesperado, na busca por um universo científico significativo e não fragmentado.

Ao propor a crítica ao conhecimento fragmentado, Morin (1991, 2000) destaca que esse tipo de conhecimento é insuficiente, propondo que seja conectado a um sentido, a um contexto. De certa forma, a proposta da LBD navega por essa significação, visto que para a aprendizagem de scriptlets, faz-se necessária a contextualização do conhecimento. Além da contextualização, vê-se também que o princípio da complexidade traz a ordem e a desordem; a construção do conhecimento é um paradoxo, no qual do caos vem a ordem e da ordem vem o caos.

Diante disso, é possível fazer uma analogia entre os autores, pois Schank (1999) faz uma crítica aos currículos das instituições de ensino, já Morin $(1991,2000)$ defende que devemos rever a ideia de currículo, pois já não atende mais os novos princípios de aprendizagem e torna-se um fardo para os educandos. Podemos relacionar a proposta de currículo como um processo prático de Schank (1999), é uma forma de criar um caos no que tradicionalmente se considera por currículo, ao mesmo tempo que o caos levaria a uma aprendizagem mais significativa, dentro de um processo mais natural (MORIN, 1991, 2000).

Para Schank (1999), é necessário “[...] começar a ajudar os alunos a adquirirem experiências naturalmente”. Diante disso, o 'aprender fazendo', automaticamente, se relaciona ao conceito de aprendizagem de Morin, o qual prevê que "[...] a educação deve favorecer a aptidão natural da mente em formular e resolver problemas essenciais e, de forma correlata, estimular o uso total da inteligência geral" (MORIN, 2000, p. 39).

Diante disso, a aquisição de scriptlets na LBD refere-se justamente às pequenas aprendizagens que geralmente são direcionadas para resolver problemas da vida cotidiana, na forma como o educando se relaciona com o mundo e com as coisas no mundo (SCHANK, 1999). Morin (1991) segue também esse princípio afirmando que é essencial pensar a "[...] complexidade onde ela aparece em geral ausente como, por exemplo, na vida cotidiana” (MORIN, 1991, p. 69).

Quando Morin (1991) disserta sobre os princípios de "auto-organização", compreendido também como "auto-eco-organização", uma vez que o indivíduo depende de suas interações com o meio social e biológico, ele apresenta o ser humano como inconstante, paradoxalmente organizado e desorganizado, logo, um ser complexo por natureza. Essa "auto-organização" é dotada de autonomia, a qual é necessária para a manutenção do ser humano enquanto ser social e histórico.

Percebe-se, então, que uma das preocupações da LBD também é a busca pela autonomia do educando, pois Schank (1999), constantemente, ressalta a importância da aquisição de scriptlets baseada nos interesses dos educandos, nas suas necessidades e em seus contextos sociais. A intenção de utilizar essas aprendizagens, em longo prazo, é de que venham, realmente, a ser empregadas na vida cotidiana, preparando o educando para o mundo, de modo a tornar-se um indivíduo mais autônomo e racional.

Como um dos fundamentos essenciais à complexidade, Morin (1991) também evidencia o papel da racionalização. De acordo com o autor, "[...] a racionalidade é o jogo, é o diálogo incessante entre o nosso espírito que cria estruturas lógicas, que as aplica sobre o mundo e que dialoga com o mundo real" (MORIN, 1991, p. 84). Para essa racionalidade acontecer, a LBD mostra-se tecnicamente capaz de suprir essa necessidade, não só pelo fato de a teoria buscar o diálogo com o mundo real por meio da prática, mas também pelo fato de que "[...] o domínio de scriptlets constrói a confiança [...] e o processo tende a levar os alunos a pensar sobre o que estão 
fazendo" (SCHANK, 1999), desse modo, a racionalidade torna-se essencial para a construção do conhecimento.

Outro princípio de Morin (1991) refere-se ao conceito de recursão organiz̨acional, o qual define indivíduos como produtos e produtores de conhecimento. Ao aprender fazendo, o educando está sujeito a contribuir para a construção dos scriptlets (produtores), ao mesmo tempo, esse educando tem uma cultura, um modo de vida, bem como de agir, o qual lhe é concedido por sua vivência em sociedade (produto).

Essa construção é dificultada, no entanto, porque, na educação em geral, o foco está em "ensinar para o teste, enfatizar o ponto de vista do instrutor, deixando os alunos anos depois com muito pouca memória do que aprenderam" (SCHANK, 1999). Desse modo, a LBD é também uma forma de deslocar (ou libertar) o indivíduo de um sistema enraizado na absorção passiva de conhecimento para uma forma ativa possibilitando assim a democratização da aprendizagem e da atuação do indivíduo enquanto ser social.

Uma das afirmações mais importantes de Morin é sobre sua clara definição de que a complexidade não é sinônimo de completude (MORIN, 1991). Não é possível saber tudo sobre todas as coisas, a propósito, a proposta da complexidade nunca foi a de formar gênios para a sociedade contemporânea, mas sim de preparar indivíduos humanos preocupados com suas ações no mundo, assim como inspirar neles a incerteza e a inconstância.

Analogamente ao pensamento de Schank (1999), nota-se essa crítica na forma como as instituições de ensino preparam os educandos para serem o que o autor chama de "miniespecialistas", fazendo-os aprender tudo sobre a sua área de estudo, sem se preocupar com o fato de essas aprendizagens serem realmente significativas. Objetivamente, a oportunidade que deve ser proporcionada pela LBD é exatamente a da quebra das aprendizagens sem significado trazendo, para um universo real, as necessidades dos educandos. Dessa maneira, desenvolve-se a criticidade sobre o modo como atuam em sociedade.

\section{CONSIDERAÇÕES FINAIS}

Diante dessa reflexão, é possível afirmar que princípios propostos por Schank (1999) podem, de maneira contextualizada, respondem a alguns dos conceitos basilares propostos por Morin (1991, 2000), conforme descrito na Tabela 1:

Tabela 1: Relação entre as Teorias da Complexidade e Learning By Doing

\begin{tabular}{|l|l|l|}
\hline \multicolumn{1}{|c|}{ Complexidade } & \multicolumn{1}{|c|}{ LBD } & \multicolumn{1}{c|}{ Semelhança } \\
\hline $\begin{array}{l}\text { Crítica ao pensamento } \\
\text { fragmentado. }\end{array}$ & $\begin{array}{l}\text { Crítica à aprendizagem } \\
\text { passiva. }\end{array}$ & $\begin{array}{l}\text { Ambas tratam do conhecimento humano } \\
\text { demonstrando como este deve ser } \\
\text { compreendido. }\end{array}$ \\
\hline $\begin{array}{l}\text { Explorar possibilidades } \\
\text { cerebrais } \\
\text { desconhecidas. }\end{array}$ & Aprendizagem inconsciente. & $\begin{array}{l}\text { As teorias defendem possibilidades de } \\
\text { conhecimento ainda não totalmente } \\
\text { compreendidas pela ciência. }\end{array}$ \\
\hline $\begin{array}{l}\text { A ação como um } \\
\text { reflexo do } \\
\text { conhecimento } \\
\text { humano. }\end{array}$ & $\begin{array}{l}\text { A prática como meio para } \\
\text { aprendizagem. }\end{array}$ & $\begin{array}{l}\text { Os autores consideram a prática/ação como } \\
\text { meio de explorar e conhecer o ambiente no } \\
\text { qual o sujeito está inserido. }\end{array}$ \\
\hline $\begin{array}{l}\text { O conhecimento é } \\
\text { passível de erro. }\end{array}$ & $\begin{array}{l}\text { A prática pode promover o } \\
\text { erro e a compreensão dele. }\end{array}$ & $\begin{array}{l}\text { As duas teorias apontam o erro como um fato } \\
\text { normal e fundamental para a construção do } \\
\text { conhecimento. }\end{array}$ \\
\hline
\end{tabular}




\begin{tabular}{|l|l|l|}
\hline $\begin{array}{l}\text { As estratégias como } \\
\text { forma de refletir sobre } \\
\text { o conhecimento. }\end{array}$ & $\begin{array}{l}\text { Os scriptlets como forma de } \\
\text { prover estratégias para a } \\
\text { resolução de problemas. }\end{array}$ & $\begin{array}{l}\text { Para Morin, é necessário criar estratégias para } \\
\text { a reflexão sobre o conhecimento, nesse } \\
\text { contexto, as experiências proveem scriptlets } \\
\text { que são usados na reflexão sobre o } \\
\text { conhecimento. }\end{array}$ \\
\hline $\begin{array}{l}\text { O conhecimento } \\
\text { precisa estar conectado } \\
\text { ao contexto do } \\
\text { educando. }\end{array}$ & $\begin{array}{l}\text { A aquisição de scriptlets } \\
\text { necessita considerar as } \\
\text { necessidades do educando. }\end{array}$ & $\begin{array}{l}\text { Os autores defendem uma educação } \\
\text { democrática, voltada para as necessidades do } \\
\text { educando. }\end{array}$ \\
\hline $\begin{array}{l}\text { Rever o currículo das } \\
\text { instituições. }\end{array}$ & $\begin{array}{l}\text { Os currículos devem prover a a } \\
\text { aprendizagem prática. }\end{array}$ & $\begin{array}{l}\text { Morin e Schank promovem uma crítica às } \\
\text { instituições de ensino. Estas necessitam rever } \\
\text { seus currículos e promover uma educação } \\
\text { significativa. }\end{array}$ \\
\hline $\begin{array}{l}\text { Aptidão natural da } \\
\text { mente em formular e } \\
\text { resolver problemas. }\end{array}$ & $\begin{array}{l}\text { Mediar as experiências para a a } \\
\text { aquisição de scriptlets de } \\
\text { maneira natural. }\end{array}$ & $\begin{array}{l}\text { Para ambos, a aquisição de conhecimento } \\
\text { deve seguir um curso natural, no qual a } \\
\text { educação deve compreender o contexto real } \\
\text { do educando. }\end{array}$ \\
\hline $\begin{array}{l}\text { A auto-organização } \\
\text { como forma de } \\
\text { manutenção do ser } \\
\text { social e histórico. }\end{array}$ & $\begin{array}{l}\text { A aquisição de scriptlets como } \\
\text { forma de preparar um } \\
\text { indivíduo autônomo. }\end{array}$ & $\begin{array}{l}\text { As teorias apontam para a necessidade da } \\
\text { formação de indivíduos autônomos, os quais } \\
\text { estejam preparados para a convivência em } \\
\text { sociedade. }\end{array}$ \\
\hline $\begin{array}{l}\text { Complexidade não é } \\
\text { completude. }\end{array}$ & $\begin{array}{l}\text { Não se deve formar } \\
\text { "miniespecialistas". }\end{array}$ & $\begin{array}{l}\text { Os autores não acreditam que a educação } \\
\text { deva formar "gênios", mas sim indivíduos } \\
\text { críticos e preparados para o mundo moderno. }\end{array}$ \\
\hline
\end{tabular}

Fonte: os autores, com base em Schank (1999) e Morin (1991, 2000).

É importante ressaltar que as duas teorias refletem uma aprendizagem significativa, a qual propõe uma educação baseada nos anseios do educando preparando-o para os desafios do cotidiano. Por esse viés, entende-se que toda aprendizagem carrega em si responsabilidades, e estas vão refletir na vida do indivíduo, na formação de seu caráter, assim como na forma como ele atuará em sociedade.

Nesse contexto, faz-se necessário compreender que a humanidade é composta de várias realidades que conversam mutuamente. Várias culturas, diversas línguas, todas fornecem uma interpretação diferente da essência humana. Além disso, como afirmou Morin, somos seres espirituais, físicos, biológicos, que se mantêm nesse meio em um ciclo inconstante na busca por equilíbrio. E se "[...] a totalidade não é verdade" (MORIN, 1991, p. 83), deve-se buscar constantemente esse equilíbrio exatamente por não sermos capazes de saber tudo, não termos certeza sobre tudo e, principalmente, não podermos contentar-nos com conhecimento de origem duvidosa.

\section{REFERÊNCIAS}

BOTO, Carlota. Um credo pedagógico na democracia escolar: algum traçado do pensamento de John Dewey. Revista Educação, v. 29, n. 3, p. 599-619, 2006.

DIAS, Celso Osório da Silva. Comunicação, epistemologia e tecnologia em Edgar Morin. 212 p. Tese, Doutorado em Comunicação Social. Programa de Pós-graduação da Faculdade de Comunicação Social, Pontifícia Universidade Católica do Rio Grande do Sul, Porto Alegre, 2007.

MORIN, Edgar. Introdução ao pensamento complexo. Lisboa: Instituto Piaget, 1991.

MORIN, Edgar. Os sete saberes necessários à educação do futuro. 2. São Paulo: Cortez, 2000. 
SCHANK, Roger Carl. Learning by doing in: dynamic memory revisited. Nova York: Cambridge University Press, 1999. p. 172-194.

\section{Informações dos autores}

Roque Corrêa Júnior

Pontifícia Universidade Católica do Paraná

E-mail: roquejunior94@hotmail.com

ORCID: https://orcid.org/0000-0002-8360-4074

Link Lattes: http://lattes.cnpq.br/5961328760557884

Dilmeire Sant'Anna Ramos Vosgerau

Pontifícia Universidade Católica do Paraná

E-mail: dilmeire.vosgerau@pucpr.br

ORCID: https://orcid.org/0000-0002-9508-0888

Link Lattes: http://lattes.cnpq.br/8594637607405428

Pura Lúcia Oliver Martins

Pontifícia Universidade Católica do Paraná

E-mail: pura.oliver@pucpr.br

ORCID: https://orcid.org/0000-0003-0300-8318

Link Lattes: http://lattes.cnpq.br/4606246142841972 